\title{
Innovation in High-End Food Service During COVID-19 Lockdowns
}

\author{
Aarni Tuomi \\ Haaga-Helia University of Applied \\ Sciences \\ aarni.tuomi@haaga-helia.fi
}

Iis Tussyadiah

University of Surrey

i.tussyadiah@surrey,ac,uk

\author{
Mark Ashton \\ University of Surrey \\ m.ashton@surrey.ac.uk
}

\author{
Hanna-Kaisa Ellonen \\ Laurea University of Applied \\ Sciences \\ hanna-kaisa.ellonen@laurea.fi
}

\begin{abstract}
COVID-19 lockdown measures have forced hospitality operators to re-configure their dynamic capabilities through innovating operational practices and pivoting traditional business models. The highend food service sector has undergone a particularly drastic shift towards a new normal. This qualitative study explores factors facilitating innovation at 16 high-end food service organizations in Finland and the UK through semi-structured expert interviews. Three key themes facilitating innovation during COVID-19 lockdowns are identified: 1) Combining high-tech and high-touch through new ways of producing and providing technology-driven service offerings, 2) Prosocial engagement, i.e. working together with multiple stakeholders to bring added value to all parties, not just the business, and 3) Reactivity, i.e. pushing the traditional boundaries of the sector through quick decision-making and constant iteration and refining of processes and procedures. Drawing our empirical findings together, innovation during COVID-19 lockdowns in high-end food service is conceptualized into three phases: React, Refine, and Reflect.
\end{abstract}

\section{Introduction}

Global efforts to curb the spread of COVID-19 have caused ripple effects that will continue to shape social, economic, and other phenomena for years to come [1]. The various national and international restrictions on peoples' movement have been particularly dramatic. While local, regional, and national lockdowns have facilitated the need to stay socially distant, strict regulations have also severely impacted industries that rely on people travelling and interacting with each other [2]. While the service sector as a whole has been hit hard, there are industries within the sector that have been under unprecedented strain due to government-mandated lockdown measures. Food service presents one such industry [3]. However, even within food service there have been winners and losers, whereby for some operators the need to close shop has meant mass-furloughing of staff and even bankruptcies, while for others it has provided a unique opportunity to innovate service offerings and pivot existing business models [4]. In essence, the exogenous shock caused by COVID-19 has shaken up companies' dynamic capabilities, whereby the new normal has required rapid re-configuring of capabilities to sense and seize emerging business opportunities as well as adjust and align existing resource bases to better fit the changing market environment. Several studies have particularly emphasized the role of information and communication technology (ICT) in producing and providing food service that is perceived as safe and compliant with e.g. social distancing measures $[5,6]$.

While the role of technology in facilitating and actioning service innovation has been widely researched [7], previous studies mostly focus on disruptive changes brought by technology-driven business model innovation and how incumbent service firms are affected by and have responded to these changes [8]. This line of research tends to contrast technology-driven vs. market-driven (technologypush vs. demand-pull) innovations in terms of their competitive and disruptive effects across the service industry $[7,9]$. However, today's innovations from food service firms are driven by the drastic change in the operational environment (i.e., lockdowns restricting physical operations), and as such do not necessarily fit the mould of technology-push or demand-pull innovation. Furthermore, innovations sparked by COVID-19 represent emergent strategies rather than planned changes, often involving a pivot to new business models or operational practices at speed. 
This presents conceptual and practical challenges to understand better how technology and other dynamic capabilities play a role in the development of innovation for firms' survival and competitiveness in the food service sector.

To address these challenges, this study adopts a qualitative approach to explore (technology-driven) innovation in the COVID-struck food service sector. The study focuses on the highest tiers of food service, i.e. high-end restaurants, cafés, and bars that have received and accrued both national and international acclaim, illustrated by Michelin-stars, AA-Rosettes, or other gourmet accolades. This is because these types of service organizations are recognized as first-movers or role models for the rest of the sector, whereby innovative new practices and procedures first adopted by the top-end of the sector tend to be mimicked by and diffused across the rest of the sector over time [10]. High-end restaurants are also often helmed by particularly influential characters (e.g. celebrity chefs), giving these service organizations (and their respective innovation practices) extended visibility and thus additional weight in influencing general discourse around industry best practice [11]. Adopting a qualitative approach to explore the innovation strategies of high-end food service organizations thus offers a useful lense to reflect on the impacts of COVID-19 lockdown measures on innovation as a process of identifying, accessing, and combining dynamic capabilities into new service offerings [12, 13]. To that end, this study seeks to address the following research question: what kinds of factors have facilitated innovation in high-end food service during COVID-19 lockdowns?

The rest of the paper is organized into five parts. In section two we define and discuss innovation in the context of service, and then highlight the notion of dynamic capabilities, linking these to how service organizations adapt to external change. In sections three and four we present the method and findings of our empirical study. In section five we discuss the implications of our findings by conceptualizing the ways in which high-end food service organizations have adapted to COVID-19 lockdowns through innovation. Finally, in section six we summarize our key findings, note the limitations of our approach, and consider avenues for future research.

\section{Innovation and dynamic capabilities}

\subsection{Innovation in service}

Innovation is, at a fundamental level, about purposeful action towards mobilizing change [11, 14]. Change may come in different forms and, as such, there are different approaches to innovation. For example, incremental innovations tend to improve existing practices through a gradual process, whereas radical innovations mark a distinct departure from the old way of doing things [15]. Similarly, modular innovations imply changes to a specific part of a larger system, whereas architectural innovation entails revamping an entire system $[16,17]$. In the context of services, Voss and Zomerdijk [18] argue that innovation may consider different elements of service, for example, the service environment, the service employee, the service delivery process, customers, or back-office functions. Helkkula, Kowalkowski and Tronvoll [19] further categorize service innovations into four archetypes: output-based, process-based, experiential, and systemic service innovations. Witell et al. [13] conclude that at its core, service innovation is about identifying, accessing, combining, and recombining available resources to improve organizations' practices in novel, unforeseen ways.

Service organizations go through change because the environments within which they operate are in constant flux. Dobbs, Manyika and Woetzel [20] see that modern companies are forced to change because of four key drivers in particular: urbanization, technology, an ageing population, and globalization. Besides these general megatrends of the 21st century, Taleb [21] argues that sometimes change is due to what he calls a 'black swan' event. These are events that are rare, random, unexpected, and as such, extremely difficult to predict or plan for [22]. The emergence of COVID-19 could be characterized as a 'black swan' event because of its devastating impact on the global economy, including the service sector [23]. Given the rapid pace and gravity with which service providers have had to adapt to the new operating environment, an upsurge in emergent service innovation could be expected.

\subsection{Dynamic capabilities}

The process of innovating, from the advent of an idea to its implementation, requires different types of resources and capabilities, from information (e.g. data, knowledge, expertise) to resources (e.g. time, space, finance) and support (e.g. backing or approval of other actors in the innovation ecosystem) [23]. In strategic management literature, the act of innovating is often discussed in relation to dynamic capabilities. Originating from Teece, Pisano and Shuen [24], the dynamic capabilities view assumes that firms differ with respect to their ability to update their capabilities when reacting to external changes. Dynamic capabilities are seen as higher-order capabilities 
needed for changing operational practices and the resource-base of the firm $[25,26]$.

The dynamic capabilities view has since established itself as one of the most influential theoretical lenses in contemporary strategic management scholarship [27]. Broadly put, dynamic capabilities can be categorized in three categories based on their functions [28]. In this paper, we follow Teece et al.'s [24] original conceptualization and categorize dynamic capabilities into sensing, seizing and reconfiguring. Sensing refers to an organization's propensity to sense new opportunities. It involves scanning and monitoring changes in the operating environment and identifying new ideas. Seizing refers to an organization's propensity to make timely marketoriented decisions by linking their innovativeness to products and markets. Finally, reconfiguring refers to an organization's propensity to change its resource base and align the firm's capabilities. These three categories of dynamic capabilities typically follow each other chronologically, starting from identifying opportunities, moving to refining the business model and finally realigning the organizational structure and culture to fit the new norm. As such, dynamic capabilities are strongly tied to business model innovation [26, 29, 30].

Under conditions where normal operational resources or capabilities are extremely scarce (e.g. due to an exogenous black swan event such as COVID19), service organizations must still be able to demonstrate strong dynamic capabilities in order to navigate through the constant changes in the external operating environment. Out of the overall resource pool available to most customer-focused service organizations, the service employee (that is, the organization's human resource) is often considered as one of the most important (and expensive) resource. However, besides service employees, service organizations have in recent years turned increasingly to information and communication technology (ICT) to increase efficiency, cut costs, and provide service in novel ways [31]. The advent of COVID-19 has exacerbated this trend, with management consultants and researchers noting a significant sectorial restructuring towards digital services, or from "hightouch" to "high-tech" $[32,33]$. To conceptualize the roles of technology in innovation, extant research has largely agreed on the definition of technology-driven and market-driven innovations [7]. Technologydriven (technology-push) innovations happen when R\&D experimentation precedes market opportunities, thus the potential market and applications are usually unknown [34]. On the other hand, market-driven (demand-pull) innovations, even when involving technology, often result from radical changes in the value propositions made to existing customers [7].

Regardless of which came first (technology-push or demand-pull), it is vital to align technology with user needs (demand) for innovations to be successful. Studying technology-driven innovations amongst retailers in the food service sector, Esbjerg et al. [35] found that when implementing innovation that related to new technology, managers were driven by benefits to customers, confirming the importance of technology-demand alignment. Consequently, when this alignment is a challenge, firms, especially newfound companies, are forced to redefine their competitive advantage and pivot their business model [36]. Garćia-Gutiérrez and Martinez-Borreguero [37] suggest the innovation pivot framework to guide firms navigating great uncertainty associated with internal and external factors. Their framework assists in fostering the creative process of generating promising applications for an innovation by interrogating the links among dynamic capabilities: innovative use of technology, the sources of sustainable competitive advantage, and the innovative business model. COVID-19 presents an exogenous challenge to existing service firms due to the extreme narrowing of the market and reduction in scale that has not been conceptualized fully in the literature on service innovation, dynamic capabilities, and business model pivot. It also marks a distinct shift in resource allocation, whereby increasing weight is given to ICT over service employees. To address this gap in existing literature, it is important to examine the interplay between service innovation and new demand exploration underlying service innovation and business model pivots in the food service industry as spurred by the COVID-19 lockdowns. Adopting an exploratory approach looking at the dynamic capabilities of service organizations representing the early adopters of new 'best practice' of an industry provides a useful lens to shed new light on innovation theory and practice [12].

\section{Method}

To identify the kinds of factors which facilitate innovation in high-end food service during COVID-19 lockdowns, this study adopted a qualitative, exploratory approach. Data were collected in JulyNovember 2020 through 16 semi-structured interviews from two countries, Finland $(n=8)$ and the UK $(n=8)$, Table 1, following the same research protocol. Adopting a purposive sampling approach, the interviews targeted top decision-makers, i.e. individuals in charge of the innovation process as well how a particular innovation was implemented at their 
organization. Targeting what Aguinis and Solarino [38] refer to as 'elite informants' was seen to yield rich insight into the strategic decision-making underlying identification of new business opportunities (i.e., sensing), developing new service offerings to fill the identified gaps in the market (i.e., seizing), and finally to effectively allocate and manage the firms' resource base to optimize service production and delivery under new conditions (i.e., reconfiguring). To facilitate social distancing amidst the pandemic, interviews were conducted online through a teleconferencing platform. The interviews were recorded, automatically transcribed, and manually anonymized. The interviews lasted for 41 minutes on average (max. 62 min, min. $36 \mathrm{~min}$ ). The interview questions revolved around four themes: 1) the innovations the food service organization had implemented during COVID19 (e.g. types of innovation and their intended outcomes), 2) the characteristics of the studied food service organization (e.g. the service concept, business model, organizational structure, resource base, level of innovativeness prior to COVID-19), 3) the innovation process (e.g. decision-making, role of dynamic capabilities, including ICT-usage), and 4) the implementation and outcome of innovation (e.g. critical success factors, potential failures, metrics).

Table 1. Characteristics of interview participants.

\begin{tabular}{lll}
\hline Id. & Position & Country \\
P1 & Sommelier/Owner & Finland \\
P2 & Chef Patron & Finland \\
P3 & Chef Patron & Finland \\
P4 & Executive Chef & Finland \\
P5 & General Manager/Owner & Finland \\
P6 & General Manager & Finland \\
P7 & Sommelier/Owner & Finland \\
P8 & General Manager & Finland \\
P9 & Executive Chef & UK \\
P10 & Restaurant Director & UK \\
P11 & Executive Chef & UK \\
P12 & Chef Patron & UK \\
P13 & Chef Patron & UK \\
P14 & Executive Chef/Owner & UK \\
P15 & Chef Patron & UK \\
P16 & Chef Patron & UK
\end{tabular}

Six of the interviews were conducted in Finnish and translated ad verbum into English (P1-4, 7-8). The consistency of the translated transcripts was checked through member checking. The remaining ten interviews were conducted in English (P5-6, 9-16). As the interviews targeted elite informants [38], i.e. leaders of some of the best food service organizations in the world, two of the 16 interviews had to be conducted via email due to extremely busy schedules (P2, P13). In these cases, the interview protocol was sent by email to participants who returned their written answers within two weeks. The interview process was conducted by two members of the research team, and after 13 interviews, the team held an internal meeting discussing the process thus far and the state of saturation (to the degree to which saturation in qualitative research can even be reached, [39]). The interviewers concluded that similar anecdotes were starting to appear frequently in participants' answers. After a further three interviews were conducted and no new themes seemed to be emerging, data saturation was deemed to have been reached and data collection was ceased. Following Tuomi et al. [40], data was analyzed thematically in three stages, whereby the analysis moved from description to abstraction through open, axial, and theoretical coding. In the end, a code tree illustrating three major themes and capturing 64 first, second, and third-order codes were established. The major themes were: 1) T1: Combining high-tech and high-touch through innovating new ways of producing and providing service offerings, 2) T2: Prosocial engagement, i.e. working together with multiple stakeholders to bring added value to all parties, not just the business, and 3) T3: Reactivity, i.e. playing the role of an 'industry leader' by pushing the traditional boundaries of the sector through quick decision-making, constant iteration and refining of processes and procedures, as well as further experimentation with ways to use ICT to provide service.

Data analysis was primarily led by one of the authors; the other two authors were kept in the loop throughout the process by discussion and sharing of notes in bi-weekly meetings facilitated by a teleconferencing and remote collaboration platform. To formally ensure analytical consistency across multiple coders, an intercoder reliability check was also conducted. The final refined code book along with a sample of random interview transcript excerpts $(n=20)$ were sent by email to two members of the research team for re-coding. Following Landis and Koch [41] and Tuomi and Tussyadiah [42], agreement between independent coders was calculated against two measures, Percent Agreement (PA) and Cohen's Kappa (CK). A good (>0.61) or very good (>0.81) agreement was established between coders across all major themes against both measures [41]. Instances where there had been disagreement were discussed on a case-by-case basis to reach consensus. Table 2 illustrates the results of the intercoder reliability check. 
Table 2. Results of intercoder reliability check.

\begin{tabular}{|c|c|c|c|c|}
\hline Theme & PA coder 1 & PA coder 2 & $\begin{array}{l}\text { CK } \\
\text { coder } 1\end{array}$ & $\begin{array}{l}\text { CK } \\
\text { coder } 2\end{array}$ \\
\hline $\mathrm{T} 1$ & 0.91 & 0.93 & 0.87 & 0.85 \\
\hline $\mathrm{T} 2$ & 0.86 & 0.73 & 0.81 & 0.70 \\
\hline T3 & 0.82 & 0.90 & 0.79 & 0.86 \\
\hline
\end{tabular}

\section{Findings}

Three major themes were found: 1) Combining high-tech and high-touch through innovating new ways of producing and providing service offerings, 2) Prosocial engagement, i.e. working together with multiple stakeholders to bring added value to all parties, not just the business, and 3) Reactivity, i.e. playing the role of an 'industry leader' by pushing the traditional boundaries of the sector through quick decision-making, constant iteration and refining of processes and procedures, as well as further experimentation with ways to use ICT to provide service.

\subsection{Combining high-tech and high-touch}

The high-end food service scene is typically known for its high-touch approach, illustrated by the labor-intensiveness of both back- and front-of-house service processes [43]. However, the need to observe social distancing rules due to COVID-19 has prompted service providers to increasingly move towards technology-facilitated service interaction (i.e., hightech). In many cases this reallocation of organizational resources [24] to facilitate the shift to high-tech seems semi-permanent. A participant noted that: "We wanted to implement a complete cashless mentality. [...] Everything was bookable online [...] Access to our menus through smartphones [...] Greater use of ApplePay [...] Introducing a new phone system with queueing advisories because of the demand [...] To keep up with email, we got a new automatic system in place that just reassures people that like, we are going to get to you." (P16). Similarly, another participant stated that "We've been trying to get paperless menus for three or four years now. [...] It was just a brilliant time to actually do it. And we 're going to stick with it." (P11). Likewise, a participant emphasized realizing the benefits of implementing online booking, something they had been skeptical about before: "Online booking only has been a huge success and something we were initially skeptical of but would now maintain looking forward to the future. By freeing up staff time, we are able to give more to making sure that stringent safety measures are maintained for staff and customers." (P13).
The importance of social media as an ICT facilitating socially distant company-customer interaction was also highlighted. A participant noted about its potential to create demand: "Social media has been amazing, and Instagram has been amazing, because everybody's on. [...] It creates demand." (P12). Others emphasized novel forms of companycustomer engagement: "We did competitions every week. [...] We were sponsored by [company name] [...] so you know they gave us free bottles of champagne, and we said, for the person that posts the best dish on Instagram, we will judge you, and you get a free bottle of champagne." (P15).

Despite being seemingly useful, challenges related to the seizing of new market share through technology [24] were also noted. A participant highlighted the limitation of integrating cyber-physical environments necessary to facilitate service delivery with multiple customers in real time: "We tried online live cooking classes with a group of people, up to 10, as well. But we had to stop that, because it was super messy [...] Very hard to get everyone to do everything at the same time, some have burnt things or missed one ingredient [...] Very hard to get everyone to finish the recipe at the same time and with the same result." (P4).

In line with previous studies of successful service innovations during COVID-19 [5], participants also emphasized their efforts to ensure the safety of customers and staff, including making significant changes to the servicescape and service delivery processes. Participants shared the efforts targeted at making the physical environment COVID-secure: "We thought, looking at the rest of the world, this isn't going to last a couple of weeks or anything. [...] Let's take the gamble and start with [...] a real proper rebuild of everything." (P15). Likewise, another participant further highlighted the reconfiguring of available resources to facilitate safe service delivery: "We spent a major portion of the budget on making the restaurant as COVID safe as possible in order to give our customers the confidence to dine with us." (P13). Others highlighted making the use of face coverings a new operational standard: "From day one of reopening, the kitchen, front of house, everyone wore masks. People feel safe. It did feel a bit weird at first, but you know now they're used to it and the front of house team can sort of learn to smile underneath the masks and things. (P15).

General challenges related to the shift to 'new normal', particularly around reorganizing existing resource base around on-demand, delivery-centered service offering during lockdown, were also noted: "I was very keen to open up a takeaway immediately, but it took a little bit of setting up because, you know, it's all about finding the right packaging, coming up with 
a menu which is suitable for people to do at home, coming up with all the instructions of how to cook it, all the labelling, all the allergens, all that sort of thing. Research, and how to market it." (P14). "Our takeaway boxes were plastic at first. This was a huge issue with our customers, who expected us to use biodegradable packaging only. So we changed that, even though it was more expensive." (P3).

Amidst these challenges some creative approaches also emerged: "Labelling, bagging all of these things [...] When you have two hundred orders to prepare, all with 16 different elements [...] Sometimes we'd miss something. And so they'd [the customers] get back to us and we'd send them the missing bits by taxi." (P8).

\subsection{Prosocial engagement}

In addition to making significant changes to the way service is produced and provided, participants stressed the importance of playing their part in ensuring the continued sustenance of the high-end food service sector by reconfiguring their firms' dynamic capabilities to sustain different stakeholders involved in the broader system of the food value chain, including suppliers, service employees, and the wider society [3, 44]: "I went to my suppliers and said to them, I know you guys are having a hard time as well. What should I have on my menu when I reopen?" (P9). "The meat suppliers were really supportive, because obviously they've got a lot more stock than what we've got to get rid of. So we worked with them. We worked with the cheese company, too, which is literally down the road. We did a cheese course. So they'd individually wrap them all in paper and write the description on each and have it in a little bag with their branding on it." (P15). "We took a pay cut on the top to be able to pay all the salaries." (P10). "We did some charity drops, like I think a lot of places did. We had thousands of pounds worth of stock in the fridges and freezers. [...] We did that to utilize that and obviously help the local community. (P9). "Sure, part of the take away was of course to keep the business afloat. But it wasn't just that. We wanted to offer something special for people to enjoy while stuck at home." (P3).

\subsection{Reactivity}

As illustrated, by dramatically shrinking the size of the available market as well as posing significant strain on dynamic capabilities required in times of normal operations, COVID-19 sparked innovative new practices and procedures hitherto unseen in the high-end food service scene. The degree of structural change in terms of reconfiguring dynamic capabilities did not go unnoticed by participants, either: "This year we've been able to broaden our thinking more than ever before. Takeaway food from a Michelin star restaurant? Wine pairings with off-the-shelf wines, at home? Incredible new ideas and great opportunities, many of which I think might stay after we get back to some form of normality." (P3). "I think a lot of highend restaurants are starting to look outside the box. We've always [...] It's all about the food, you know [...] That involves quite often having tunnel vision [...] I think that might be changing somehow." (P12).

In terms of emergent dynamic capabilities, new, innovative ways of utilizing available resources seemed to require flexibility, fast decision-making, and iteration. "We started doing a lot of training so that people could be more flexible in which department they work in. And right when we first reopened in July, you know, within somebody's five day working week they could be working in maybe three, four different departments to try and cover the business where we needed it. [...] That was quite a big change." (P15). "We'll brainstorm between each other and then this is what we do. And then after, well, the next day, you need to act." (P10). "Within two days we had the shop online [...] and that evolved over the course of the three months of lockdown." (P11). "As far as innovation's concerned, that's key for me. [...] We have a lot of repeat business [...] They would be horrified if there was no change on the menu. So, it's really important to keep changing and keep coming up with new ideas, whether that's in service, in the bar, or on the menu." (P14). "We looked at what they were doing in Copenhagen, and decided to do the same. So we got these winter gardens, like small glass houses, built on the terrace. We started with one, just to sort of see if there would be interest. After we put it online, all the slots for it were sold out for the rest of the year in like a day. [...] We got another one. [...] And then a third. Now finally we have four, as we ran out of space to add more. All are fully booked for the season." (P8).

\section{Discussion}

\subsection{Innovation during COVID-19}

Government-mandated restrictions on movement have forced high-end food service operators to radically change their business models and operational practices, effectively transforming their dynamic capabilities and in doing so giving rise to a plethora of novel service innovations. Contrasting these against conceptualizations of service innovation put forward in previous literature, changes can be observed across 
several fronts [18]: new ways of delivering service (e.g. ready-to-eat or finish-at-home takeaway or delivery offering), radical changes to the service environment/servicescape (e.g. installing plexiglass screens, revamping layout), transforming back-office functions (e.g. adopting new ordering or payment system), affecting the service employee (e.g. harnessing slack resources to help local communities), and changing the traditional service interaction with the customer (e.g. fostering new ways of driving social engagement such as virtual tastings). Interestingly, most of these innovations seem to interlink, rather than strictly separate, between the different innovation types put forward by Helkkula, Kowalkowski and Tronvoll [19]. For example, launching a new meal kit offering could be seen as primarily an output-based service innovation; however, at the same time the innovation also brings significant changes to the existing service production and delivery processes as well as the customer experience of consuming the service. From an innovation ecysystems point of view [44], pivoting the entire business model from full service to take-away marks a radical shift from the status quo and a systemic change in the way service is usually produced and provided. In practice this means changes to how firms manage their dynamic capabilities [24].

As discussed by Hossain [45], research on innovations that occur under extreme constraint typically focuses on developing economies, where the overall distribution of resources and availability of dynamic capabilities are scarce by default. In other words, where the supporting infrastructure has not yet been established, innovative service companies have to make do with limited resources. This leads to new practices being conceived or conventional practices being leapfrogged purely out of necessity [44]. The type of radical, sudden reduction of market due to state interventions we have seen amidst COVID-19 differs from previous conceptualizations of such frugal innovation dramatically, as it brings the neoliberal economic model to the fore. In their comprehensive review of frugal innovations, Weyrauch and Herstatt [46] arrived at three defining criteria: substantial cost reduction, concentration on core functionalities, and optimized performance level. Service innovations arising under COVID-19 lockdown-measures seem to resonate well with these, while also emphasizing several dynamic capabilities which facilitate innovation adoption from the spark of an idea to its subsequent implementation.

First, most of the innovations discussed herewith make active use of ICT, whether that is to facilitate service interaction (e.g. digital menus, online ordering systems, quizzes on social media) or promote and discuss new service offerings (e.g. posting pictures of weekly take away menu on Instagram). In order to effectively manage the shift towards greater technology-utilization, service operators need to possess a particular set of capabilities to recognize and seize opportunities for implementing technology as well as technology-specific know-how to capitalize successfully on identified opportunities. This marks a shift from a human resource dominant view to an ICT dominant view in capability and resource allocation in high-end food service. Previous studies have suggested an increased influence of ICT systems over human labor in food service contexts [42], whereby service organizations' technology uptake is driven by both the availability and relative ease of adopting ICT (technology-push) innovation, as well as the apparent, perhaps previously unexpected appetite for digital services even in the high-end service segment (demand-pull) [5, 7].

Second, innovations occurring under COVID-19 lockdown conditions require fast decision-making and organizational and operational flexibility. As the operational environment is in constant flux, service providers have to operate under high degrees of uncertainty. Doing so requires coping with stress and an ability to make fast decisions on how best to utilize scarce resources. The rapid shrinking of the market exacerbates the effects of constraints on innovative behavior [48]. Particularly impacted are input and process constraints. In terms of input constraints, financial and human resources as well as time seem to play a key role, while in terms of process constraints the formalization of the new product development process (or the lack thereof, [49, 50]) seems most significant.

Third, the ability to course correct if and when decisions made or practices implemented require changing becomes imperative. High-end food service operators need to adopt a mindset of continuous improvement, whereby innovations gradually move from being mere 'minimum viable products' [51] to encompassing new features in response to market needs [35]. This iterative process of defining and refining value propositions over a short period of time allows service operators to concentrate on their core functionalities and optimize performance levels by identifying the characteristics of service innovation (e.g. high tech vs. high touch) most suitable for their respective target market and reconfiguring their dynamic capabilities accordingly.

\subsection{Showcasing dynamic capabilities}

Based on our empirical research, the ways in which high-end food service organizations have adapted to 
the exogenous shock of government-mandated COVID-19 lockdowns can be conceptualized into three distinct phases of innovating operational practices and business model: 1) React, 2) Refine, 3) Reflect.

In the first phase (React), the emphasis is placed on the immediate reaction to the shock, illustrated by making the decision to pivot, e.g. through innovating a new service offering, or not. While this is akin to Teece, Pisano and Shuen's [24] original conceptualization of 'sensing', the extremely rapid reduction of market and the uncertainty under which initial decisions have to be taken make this phase more ad-hoc than the typical scanning of the market environment for opportunities to exploit [52]. In the second phase (Refine), the emphasis shifts from adhoc decision-making under uncertainty to addressing challenges and knock-on effects which emerge from the business model pivot, e.g. going through multiple rounds of iteration to improve the initial service offering or reaching out to the external stakeholder network or innovation ecosystem [44] to provide assistance to the wider value chain. This marks a departure from seizing [24] as one of the core drivers of change in this phase is the desired longevity of the entire system rather than the improved performance of one individual actor [30]. Finally, in the third phase (Reflect), the emphasis shifts again to strategically aligning pre-pivot dynamic capabilities with the new operational reality, e.g. making a permanent shift to a paperless menu or an online booking system. While this phase illustrates reconfiguring $[24,26]$, it seems less concerned with optimizing resource use and more aimed at future-proofing service practices. Based on our empirical findings this phase also places a particularly strong emphasis on key individuals, with strategic decision-making stemming from the personal beliefs and ideals of the executive team rather than e.g. fiscal planning [53].

The three phases of adapting to COVID-19 lockdowns identified herewith simultaneously support and extend previous conceptualizations on the impact of dynamic capabilities for creating and defining defensible new business models through innovation $[24,26,30]$. Our study offers a unique empirical contribution to existing literature on dynamic capabilities and innovation management by illustrating the rapid learning loop high-end food service organizations have been forced to undertake due to COVID-19 lockdowns. Further, perhaps due to the wide-reaching nature of this particular exogenous shock, our findings complement recent literature by further highlighting the importance of open, multistakeholder collaboration and sharing of ideas and resources [50] as opposed to more traditional defending of intellectual property [26]. To collate our findings, Figure 1 presents a conceptualization of high-end food service organizations' innovation process during COVID-19 lockdowns.

\begin{tabular}{|l|}
\hline \multicolumn{1}{|c|}{ Phase 1 - React } \\
Driver: Need to come up with \\
something quick to take to market
\end{tabular}

Figure 1. Innovation in high-end food service.

\section{Limitations \& further research}

This study contributes to existing research on service innovation, dynamic capabilities, and business model pivot by exploring innovation strategies at highend food service organizations during COVID-19 lockdowns. In doing so, this study answers the call by Schilke et al. [27] by extending the discourse around dynamic capabilities into specific sectors of economic activity. Three key themes facilitating innovation during COVID-19 lockdown are identified: 1) Combining high-tech and high-touch through new ways of producing and providing technology-driven service offerings, 2) Prosocial engagement, i.e. working together with multiple stakeholders to bring added value to all parties, not just the business, and 3) Reactivity, i.e. pushing the traditional boundaries of the sector through quick decision-making and constant iteration and refining of processes and procedures. Building on Teece's [24] original view on dynamic capabilities, innovation during COVID-19 lockdowns in high-end food service is conceptualized as a process consisting of three subsequent phases, React, Refine, and Reflect. The conceptualization is put forward both as a foundation for future research as well as a tool to guide managerial decision-making.

In terms of limitations, despite collecting data from two countries (Finland and the UK), the study presented here has limitations that should be considered. First, only high-end food service 
organizations were analyzed here. Even though these were deemed as a meaningful, 'best practice' example for adopting service innovation during COVID-19 lockdowns, extending the study to include operators with multiple centrally branded sites would have provided interesting insight into service innovation across larger, presumably less agile organizations. A particularly interesting angle to this line of study would be to explore the differences in innovation practices between company-owned and franchised locations. Second, the study was purely qualitative and focused solely on restaurants located in Finland and the UK. Replicating the study with different methodological approaches and in other cultural contexts with different norms and conventions regarding e.g. service or organizational culture might produce a richer picture of innovation efforts, including dynamic capabilities driving and/or hindering innovation [54]. Third, the exact lockdown measures adopted have been slightly different in different countries. This poses both limitations and opportunities for future research. For example, the relative length of lockdowns might influence the types and complexity of innovation which emerge, as well as the dynamic capabilities that underlie innovation adoption. Further studies should therefore compare and contrast emergent innovation and dynamic capabilities under different types of lockdowns. For example in the context of the UK, future research could comparatively study lockdowns in Scotland, England, Wales, and Northern Ireland, as well as more regionally, e.g. between Tier 1, Tier 2, and Tier 3 lockdowns.

\section{References}

[1] K. Yu, and K. Aviso, "Modelling the economic impact and ripple effects of disease outbreaks", Process Integration and Optimization for Sustainability 4, Springer, 2020, pp. 183186.

[2] I. Gallego, and X. Font, "Changes in air passenger demand as a result of the COVID-19 crisis: using big data to inform tourism policy", Journal of Sustainable Tourism, Taylor and Francis, 2020.

[3] P. Jones, and D. Comfort, "A commentary on the COVID-19 crisis, sustainability and the service industries", Journal of Public Affairs, Wiley, 2020.

[4] E. Goddard, "The impact of COVID-19 on food retail and food service in Canada: Preliminary assessment", Canadian Journal of Agricultural Economics 68(2), Wiley, 2020, pp. 157-161.

[5] H. Shin, and J. Kang, "Reducing perceived health risk to attract hotel customers in the COVID-19 pandemic era: focused on technology innovation for social distancing and cleanliness", International Journal of Hospitality Management 91, Elsevier, 2020.
[6] A. Sharma, H. Shin, M.J. Santa-Mariá, and. J.L. Nicolau, "Hotel's COVID-19 innovations and performance", Annals of Tourism Research 88, Elsevier, 2021.

[7] S.R. Habtay, "A Firm-Level Analysis on the Relative Difference between Technology-Driven and Market-Driven Disruptive Business Model Innovations", Creativity and Innovation Management, Wiley, 2012.

[8] D. Guttentag, "Airbnb: disruptive innovation and the rise of an informal tourism accommodation sector". Current Issues in Tourism 12, Taylor and Francis, 2015, pp. 1192-1217.

[9] W.E. Souder, "Improving productivity through technology push". Research Technology Management, 32(2), Taylor and Francis, 1989, pp. 19-24.

[10] T. Greenhalgh, G. Robert, F. Macfarlane, P. Bate, and O. Kyriakidou, "Diffusion of innovations in service organizations: Systematic review and recommendations". Milbank Quarterly 82(4), Wiley, 2004, pp. 581-629.

[11] Opazo, P., Appetite for Innovation. Columbia University Press, New York, 2016.

[12] K. Eisenhardt, "Building theories from case study research", Academy of Management Review 14(4), Academy of Management, 1989, pp. 532-550.

[13] L. Witell, H. Gebauer, E. Jaakkola, W. Hammedi, L.Patricio, and H. Perks, "A bricolage perspective on service innovation", Journal of Business Research 79, Elsevier, 2017, pp. 290-298.

[14] Trott, P., Innovation management and new product development. 5th ed. Pearson Education Limited, Harlow, 2012.

[15] H. Snyder, L. Witell, A. Gustafsson, P. Fombelle, and P. Kristensson, "Identifying categories of service innovation: A review and synthesis of the literature". Journal of Business Research 69, Elsevier, 2016, pp. 2401-2408.

[16] R. Henderson, and K. Clark, "Architectural Innovation: The Reconfiguration of Existing Product Technologies and the Failure of Established Firms", Administrative Science Quarterly 35(1), SAGE, 1990, pp. 9-30.

[17] Y-C. Chuo, H. Chuang, and B. Shao, "The impact of e-retail characteristics on initiating mobile retail services: A modular innovation perspective". Information \& Management 53, Elsevier, 2015, pp. 481-492.

[18] C. Voss, and L. Zomerdijk, Innovation in Experiential Services - An Empirical View. In: DTI (ed). Innovation in Services, DTI, London, 2007, pp. 97-13.

[19] A. Helkkula, C. Kowalkowski, and B. Tronvoll, "Archetypes of service innovation: Implications for value cocreation". Journal of Service Research 21(3), SAGE, 2018, pp. 284-301.

[20] Dobbs, R., Manyika, J., and Woetzel, J., No ordinary disruption: the four global forces breaking all the trends, Public Affairs, New York, 2015.

[21] Taleb, N.N., The Black Swan: the impact of the highly improbable, Penguin Books, London, 2008.

[22] T. Wind, M. Rijkeboer, G. Andersson, and H. Riper, "The COVID-19 pandemic: The 'black swan' for mental health care and a turning point for e-health". Internet Interventions 20, Elsevier, 2020.

[23] I. Rodriguez-Sanchez, A. Williams, and M. Brotons, "The innovation journey of new-to-tourism entrepreneurs", Current Issues in Tourism, Taylor and Francis, 2017. 
[24] D. Teece, G. Pisano, and A. Shuen, "Dynamic capabilities and strategic management". Strategic Management Journal 18, Wiley, 1997, pp. 509-533.

[25] V. Ambrosini, and C. Bowman, "What are dynamic capabilities and are they a useful construct in strategic management?" International Journal of Management Reviews 11, Wiley, 2009, pp. 29-49.

[26] D. Teece, "Business models and dynamiccapabilities". Long Range Planning, 51(1), Elsevier, 2018, pp. 40-49.

[27] O. Schilke, S. Hu, and C. Helfat, "Quo vadis, dynamic capabilities? A content-analytic review of the current state of knowledge and recommendations for future research". Academy of Management Annals 12(1), Academy of Management, 2018, pp. 390-439.

[28] H-K. Ellonen, A. Jantunen, and O. Kuivalainen, "The role of dynamic capabilities in developing innovation-related capabilities", International Journal of Innovation Management 15(3), World Scientific, 2011, pp. 459-478.

[29] L. Achtenhagen, L. Melin, and L. Naldi, "Dynamics of business models - strategizing, critical capabilities and activities of sustained value creation". Long Range Planning 46(6), Elsevier, 2013, pp. 427-442.

[30] N. Bocken, and T. Geradts, "Barriers and drivers to sustainable business model innovation: Organization design and dynamic capabilities". Long Range Planning 53(4), Elsevier, 2020.

[31] E. Ashcroft, A. Tuomi, M. Wang, and D. Solnet, "Resistance to the adoption of ICTs in independent restaurants: insights from China and the UK", e-Review of Tourism Research (16/2-3), Texas A\&M University, 2019 pp. 105-114.

[32] A. Baig, B. Hall, P. Jenkins, E. Lamarre, and B. McCarthy, "The COVID-19 recovery will be digital: A plan for the first 90 days, McKinsey, 2020.

[33] I. Mizrachi, and U. Gretzel, "Collaborating against COVID19: Bridging travel and travel tech". Information Technology \& Tourism 22, Springer, 2020, pp. 489-496.

[34] D.C.-L. Kuo, C-C. Lin, and J-L. Yang, "Reconsidering the role of brainstorming in the marketing of technologydriven innovation", International Journal of Technology Marketing 6(1), 2011, InderScience, 2011, pp. 4-16.

[35] L. Esbjerg, S. Burt, H. Pearse, and V. Glanz-Chanos, "Retailers and technology-driven innovation in the food sector: caretakers of consumer interests or barriers to innovation?" British Food Journal, 118(6), Emerald, 2016, pp. 1370-1383.

[36] S.S. Bajwa, X. Wang, A.N. Duc, R.M. Chanin, R. Prikladnicki, L.B. Pompermaier, and P. Abrahamsson, "Start-Ups must be ready to pivot". IEEE Software, IEEE Computer Society, 2017, pp. 18-22.

[37] I. Garćia-Gutiérrez, and F.J. Martinez-Borreguero, "The innovation pivot framework: Fostering business model innovation in startups". Research-Technology Management, 59(5), Taylor and Francis, 2016, pp. 48-56.

[38] H. Aguinis, and A. Solarino, "Transparency and replicability in qualitative research: the case of interviews with elite informants", Strategic Management Journal 40, Wiley, 2019, pp. 1291-1315.

[39] V. Braun, and V. Clarke, "To saturate or not to saturate? Questioning data saturation as a useful concept in thematic analysis and sample-size rationales" Qualitative Research in
Sport, Exercise and Health, Taylor and Francis, 2019, pp. $1-16$.

[40] A. Tuomi, I. Tussyadiah, E. Ling, G. Miller, and G. Lee, " $\mathrm{x}=($ tourism_work $) \mathrm{y}=(\operatorname{sdg} 8)$ while $\mathrm{y}=$ true: $\operatorname{automate}(\mathrm{x})$ ", Annals of Tourism Research, Elsevier, 2020.

[41] J.R. Landis and G.G. Koch, "The measurement of observer agreement for categorical data". Biometrics 33, Wiley, 1979, pp. $159-174$.

[42] A. Tuomi, and I. Tussyadiah, "Building the sociomateriality of food service". International Journal of Hospitality Management 89. Elsevier, 2020.

[43] Davis, B., Lockwood, A., Alcott, P., and Pantelidis, I., Food and Beverage Management, 6th ed., Routledge, London, 2018.

[44] F.P. Appio, F. Frattini, A.M. Petruzzelli, and P. Neirotti, "Digital transformation and innovation management: A synthesis of existing research and an agenda for future studies", Journal of Product Innovation Management 38(1), Wiley, 2021, pp. 4-20.

[45] M. Hossain, "Frugal innovation: a review and research agenda”. Journal of Cleaner Production 182, Elsevier, 2018, pp. 926-936.

[46] C.K. Prahalad, and R.A. Mashelkar, "Innovation's holy grail". Harvard Business Review 88(7/8), Harvard Business School Publishing Corporation, 2010, pp. 132- 141.

[47] T. Weyrauch, and C. Herstatt, "What is frugal innovation? Three defining criteria". Journal of Frugal Innovation 2(1), Springer, 2016.

[48] O. Acar, M. Tarakci, and D. van Knippenberg, "Creativity and innovation under constraints: a cross-disciplinary integrative review", Journal of Management 45(1), SAGE, 2018, pp. 96-121.

[49] F. Damanpour, "Organizational innovation: A metaanalysis of effects of determinants and moderators", Academy of Management Journal 34, Academy of Management, 1991 pp. 555-590.

[50] L.L. Gilson, J. Mathieu, C. Shalley, and T. Ruddy, "Creativity and standardization: Complementary or conflicting drivers of team effectiveness?" Academy of Management Journal 48, Academy of Management, 2015, pp. 521-531.

[51] Ries, E., The lean startup: how today's entrepreneurs use continuous innovation to create radically successful businesses. Crown Business, New York, 2011.

[52] S. Campo, A.M. Díaz, and M.J. Yagüe, “ Hotel innovation and performance in times of crisis", International Journal of Contemporary Hospitality Management 26(8), Emerald, 2014, pp. 1292-1311.

[53] W. Batat, "How Michelin-starred chefs are being transformed into social bricoleurs? An online qualitative study of luxury foodservice during the pandemic crisis", Journal of Service Management 32(1), Emerald, 2021, pp. 87-99.

[54] A. Tuomi, I. Tussyadiah, and M. Ashton, "COVID-19 and Instagram: digital service innovation in top restaurants", Information and Communication Technologies in Tourism, Springer, 2021, pp. 464-475. 